risk of obesity and serious adult health problem such as cardio vascular disease, diabetes cancer, hypertension, psychological problem, arthritis, arthrosclerosis and diminished physical abilities.

Conclusion Due to dramatic increase in epidemiology of obesity and related health problem we have to prevention of it from fetal period and so we should start it before pregnancy with controlling intervention causes of obesity in mother and provide appropriate educating and counseling. Furthermore follow up care during pregnancy infancy and child hood is needed to reduce risk of diseases that has relation to obesity.

\section{NEWBORN AUTOPSIES: EXPERIENCE OF A REFERRAL LEVEL III NEONATAL INTENSIVE CARE UNIT IN TURKEY}

doi:10.1136/archdischild-2012-302724.1723

${ }^{1} \mathrm{H}$ Tatar Aksoy, ${ }^{1} S S$ Oguz, ${ }^{1} \mathrm{~N}$ Uraş, 10 Ö Erdeve, ${ }^{2} \mathrm{H}$ Bayramoğlu, ${ }^{2} \mathrm{~S}$ Zergeroğlu, ${ }^{3} \mathrm{U}$ Dilmen. 'NICU, Zekai Tahir Burak Maternity and Teaching Hospital, Department of Neonatology; ${ }^{2}$ Pathology, Zekai Tahir Burak Maternity and Teaching Hospital; ${ }^{3}$ Zekai Tahir Burak Maternity and Teaching Hospital/YIldırım Beyazıt University Department of Pediatrics, Ankara, Turkey

Aim Neonatal autopsies is a guide to explore the causes of the perinatal mortalities which is important marker for evaluation of the health policies. Multidisciplinary approach which includes obstetrician, pediatrician, pathologist and geneticist is required for the neonatal autopsies. We aimed to evaluate the neonatal autopsies in our center.

Methods Thirty-eight neonatal autopsies performed between January 2009 and December 2010 were evaluated in respect to demographic characteristics, clinical and pathological diagnosis retrospectively.

Results 7055 neonates were administered to our NICU between January 2009 and December 2010. 404 of the neonates passed away $(5.7 \%)$. Only the $38(9.4 \%)$ of the neonates' parents give permission for autopsy. Of these neonates were 15 female (39\%) and 23 male (61\%). Sixty percent of these neonates were premature. Prematurity was higher in male neonates ( $\mathrm{p}=0.001)$. Median gestational age was 32 (22-41) weeks. Median overall survival of the neonates were 4 (0-80) days. Eighty-three percent of the clinical diagnoses were correlated with the pathological diagnosis. Sixty percent of the clinical and pathological diagnoses were cardiovascular anomalies, diaphragmatic hernia, perinatal asphyxia and prematurity. Two neonates had pneumonia diagnosis by the autopsy. Only one of the neonate's placenta had chorioamnionitis.

Conclusion Neonatal autopsy rates should be increased to decrease the neonatal mortality rate in our country. Neonatal autopsies should be done with multidisciplinary approach and become prevalent and get more progress in our country.

\section{INEXPENSIVE HOMEMADE AGAR-BASED MODELS FOR ULTRASOUND-GUIDED CENTRAL VENOUS CATHETERIZATION TRAINING PROGRAMS}

doi:10.1136/archdischild-2012-302724.1724
N Pozzi, A Scoppa, L Orfeo. Neonatal and Pediatric Intensive Care Unit, 'G. Rummo' Hospital, Benevento, Italy

Background and Aims Central venous catheterization (CVC) plays a central role in patient management in intensive care settings. Compared with the use of traditional anatomical landmarks, ultrasound (US)guidance is associated with higher success rate and fewer mechanical complications. In order to implement the use of US-guided CVC in our Neonatal and Paediatric Intensive Care Unit, we organized a hands-on training program based on the use of agar-handmade models.

Methods Two different models were constructed to simulate vessels, as described by S. Di Domenico et al in Journal of Ultrasound (2008). In model A the vessels were visualized under a flat surface in both transverse and longitudinal scans, whereas in model B the vessels were punctured under a curved surface and the Doppler function was demonstrated. The training session began with a 40-minute lecture followed by the hands on session. We trained 10 paediatric intensivists. Each test was considered completed when participants were able to position the needle correctly on the "first attempt".

Results $60 \%$ of trainees correctly positioned the needle at the first test on model A, whereas only $20 \%$ on model B because of the more complicated technique. The percentage of participants who achieved correct needle position increased steadily with repeated punctures showing a quick acquisition of the basic skills of US-guided puncture.

Conclusions Agar-based models are useful tools for teaching the basic hand-eye coordination skills of ultrasound-guided CVC thus reducing hazardous attempts on real patients and facilitating the introduction of this technique in clinical practice.

\section{SUCCESSFUL MEASURES TO DECREASE HOSPITAL LENGTH OF STAY IN GENERAL PAEDIATRC WARD}

doi:10.1136/archdischild-2012-302724.1725

MM Abou Al-Seoud, IS Ahmed, SS Adham. Paediatric Department, King Fahad Armed Forces Hospital, Jeddah, Saudi Arabia

\section{ELOS $=$ Expected LOS ALOS $=$ Average LOS}

Background and Aims With the increasing demands on health care services a reduction in hospital length of stay (LOS) became a necessity. The number of patients admitted to the 40 beds paediatric ward at KFAFH has increased by $40 \%$ in 2011 . The department has taken measures to optimize beds utilization.

Methods ALOS for the commonest diseases requiring admissions was calculated retrospectively for the year 2007 and was found to be higher than the reported values.

The following steps were implemented:

- Increase awareness and feedback in January 2008

- Update Practice Guide lines in April 2008.

- Multidisciplinary Discharge Planning team in March 2009.

- Consultant profiling in October 2010.

- Forms for prolonged LOS justification in November 2010

- ELOS included in history and physical forms in October 2011

- Cards for ELOS in November 2011.

Abstract 1725 Table 1 Average length of stay in days per disease

\begin{tabular}{lccccccccc}
\hline Year & Asthma & Bronchiolitis & $\begin{array}{c}\text { Diabetes } \\
\text { Mellitus }\end{array}$ & Gastroenteritis & Pneumonia & $\begin{array}{c}\text { Meningitis } \\
\text { suspected }\end{array}$ & $\begin{array}{c}\text { Sepsis } \\
\text { suspected }\end{array}$ & $\begin{array}{c}\text { Sickle Cell } \\
\text { Disease }\end{array}$ & Seisures \\
\hline 2007 & 4.8 & 6.2 & 3.4 & 3.5 & 7.1 & 5.8 & 5.1 & 4.5 \\
2008 & 4 & 3.7 & 2.1 & 3.1 & 4.8 & 5 & 5.1 & 5 \\
2009 & 3.1 & 3.2 & 2.8 & 2.7 & 3.6 & 3.7 & 3.4 & 3.6 & 4.8 \\
2010 & 2.73 & 3.73 & 3.09 & 2.55 & 3.08 & 3.4 & 3.77 & 4.03 \\
2011 & 2.15 & 2.78 & 2.23 & 2.66 & 3.15 & 2.35 & 3.75 & 3.83 \\
\hline
\end{tabular}

